Two of the irradiated samples were heated at $90^{\circ} \mathrm{C}$. for $2 \mathrm{hr}$. without significant change in the percentage of material which was soluble in benzene. When phosphonitrilic chloride is polymerized by heating to $250^{\circ} \mathrm{C}$. a long chain rubber is formed; no sign of this was seen in any of the irradiated specimens.

The specimens were extracted with benzene, in which the polymerized phosphonitrilic chloride is insoluble; in no case was the amount of insoluble matter significantly different from that of the starting material. This was approximately 3 per cent which presumably represents low molecular weight linear polymers in the commercial mixture.

Further specimens which were irradiated by means of a linear accelerator up to $10^{\circ}$ rads, also showed no signs of polymerization. As this is three orders of magnitude greater than the dose ${ }^{3}$ required to initiate the polymerization of styrene it would appear that free radicals do not initiate the polymerization of phosphorus nitrilic chlorides.

For all these irradiations I am indebted to Dr. R. Roberts and the Technological Irradiation Group of the Atomic Energy Research Establishment, Harwell.

53 Cherryburn Gardens,

Thomas R. ManLey

Newcastle upon Tyne 4.

1 Patat, F., and Kallinsky, F., Makromol. Chem., 6, 292 (1951).

Restaino, A. J., Mesrobian,' R. B., Morawitz, H., Ballantine, D. S Dienes, G. J., and Metz, D. J., J. Amer. Chem. Soc., 78, 2939 (1956).

s Bouby, L., Chapiro, A., Magat, M., Migirdicyan, E., Prevot-Bernas, A., Reinisch, L., and Sebban,'J., International Conference on Peaceful Uses of A tomic Energy, Geneva, 1955, 7, 529.

\section{A Method for Determining Carbon-I4 by Combustion using Calcium Carbonate}

When organic material is to be analysed quantitatively for the content of carbon-I4 by combustion a standard method is to convert all the carbon into carbon dioxide which is then absorbed in a solution of sodium hydroxide ${ }^{1}$. The carbonate thus formed is then precipitated by the addition of barium chloride and the total amount of carbon present determined by back titration with hydrochloric acid. The barium carbonate is collected in a manner suitable for counting

Precipitation by barium chloride is convenient because accurate back titration is possible, and the precipitate can be collected fairly easily on a filter paper to give an even deposit suitable for counting. Where the total amount of carbon in the sample is small, the high atomic weight of barium is advantageous in bulking up the precipitate, but it also carries the disadvantage that there is high self absorption and consequently in comparison with lighter elements the sensitivity of counting is reduced.

Thus when there is adequate carbon available (in excess of $10 \mathrm{mgm}$. for a $2 \cdot 4 \mathrm{~cm}$. diameter end counting window) a carbonate formed from a lighter metal can give valuable extra sensitivity which may be especially needed when the material being assayed is of low activity.

Of the commoner metals with a low atomic weight only calcium carbonate gives a highly insoluble carbonate necessary for quantitative analysis. It has been found (Table 1 ) that when a comparison is made between precipitates to 'infinite thickness' of barium carbonate and calcium carbonate prepared from material of the same specific activity calcium carbonate gives an increased counting rate over barium carbonate by a factor of $1 \cdot 85 \pm 0 \cdot 08$ (cf. the molecular weight ratio of barium carbonate to calcium carbonate of $1 \cdot 98: 1)$.
Unfortunately precipitates of calcium carbonate formed by adding calcium chloride to mixtures of sodium hydroxide and sodium carbonate show a tendency to be gelatinous, and titration is made difficult and irreproducible by fading end-points. The calcium carbonate crystals which form on stand. ing may also be large and thus tend to form uneven preparations because filtration is too rapid.

It has been established that these difficulties can be avoided by adding magnesium chloride to the calcium chloride-a convenient proportion is one part magnesium chloride to two parts calcium chloride. With this mixture, back titration is consistent and reliable when thymol blue is employed as the indicator. The end-point is not so readily recognized when the mixture of the calcium and magnesium chloride is substituted for barium chloride; but a warning of the approach of the end-point is given by a change in colour from blue to grey. Titration should not be carried out until sufficient time has elapsed for precipitation to be completed. About $1 \mathrm{hr}$. has been found to be satisfactory for a wide range of conditions. The precipitates formed are not gelatinous, and the crystals are fine enough to give good filter preparations which can be dried without the cracking and distortions which may be produced by precipitates of barium carbonate. Moreover, the addition of magnesium chloride gives precipitates which show less tendency to stick to the flask.

These findings are based on a series of tests over a range of total alkalinities and ratios of sodium hydroxide to sodium carbonate (Table 1). Precipita-

\begin{tabular}{|c|c|c|c|c|c|c|c|}
\hline \multirow{3}{*}{$\begin{array}{l}\text { A]kali } \\
\text { concen- } \\
\text { tration } \\
\text { (Normality) } \\
\text { High } \\
\mathrm{N}=0.4\end{array}$} & \multicolumn{4}{|c|}{$\begin{array}{l}\text { TABLE } 1 . \\
\text { ation Accuracy } \\
\text { of Theoretical } \\
\text { Equivalent }\end{array}$} & \multicolumn{3}{|c|}{$\begin{array}{c}\text { Counting Sensitivity } \\
\text { Ratio }\end{array}$} \\
\hline & $\begin{array}{l}\text { Ratio } \\
\mathrm{NaOH}_{\mathrm{Na}_{2} \mathrm{CO}_{3}}\end{array}$ & $\mathrm{BaCl}_{2}$ & $\mathrm{CaCl}_{2}$ & $\begin{array}{l}\mathrm{CaCl}_{2} \\
+\mathrm{MgCl}_{2}\end{array}$ & $\mathrm{BaCl}_{2}$ & $\mathrm{CaCl}_{2}$ & $\begin{array}{l}\mathrm{CaCl}_{2} \\
+\mathrm{MgCl}_{2}\end{array}$ \\
\hline & $\begin{array}{l}1: 1 \\
1: 3\end{array}$ & $\begin{array}{l}97 \\
98\end{array}$ & $\begin{array}{l}85 \\
90\end{array}$ & $\begin{array}{l}95 \\
96\end{array}$ & 1 & 1.83 & $\begin{array}{l}1.77 \\
1.77\end{array}$ \\
\hline $\begin{array}{l}\text { Medium } \\
\mathbf{N}=0.2\end{array}$ & $\begin{array}{l}1: 3 \\
3: 1 \\
1: 1 \\
1: 3\end{array}$ & $\begin{array}{l}90 \\
100 \\
101 \\
100\end{array}$ & $\begin{array}{r}90 \\
92 \\
103 \\
106\end{array}$ & $\begin{array}{r}90 \\
100 \\
100 \\
101\end{array}$ & $\begin{array}{l}1 \\
-1 \\
1\end{array}$ & $1 \overline{1 \cdot 96}$ & $\frac{1.76}{1.83}$ \\
\hline $\mathrm{Now}=0 \cdot 1$ & $\begin{array}{ll}3: 1 \\
1 \\
1 & 1 \\
1 & 3\end{array}$ & $\begin{array}{l}100 \\
100 \\
100\end{array}$ & $\begin{array}{r}99 \\
109 \\
107\end{array}$ & $\begin{array}{l}100 \\
101 \\
102\end{array}$ & $\begin{array}{l}1 \\
1 \\
1 \\
1\end{array}$ & $\begin{array}{l}1.87 \\
1.87 \\
1.96\end{array}$ & $\begin{array}{l}1.70 \\
1.88 \\
1.79 \\
1.93\end{array}$ \\
\hline
\end{tabular}

Normal hydrochloric acid was used for titration throughout.

ting agents were all added in excess. All precipitates were prepared by filtration on to filter paper disks to 'infinite thickness' (more than $100 \mathrm{mgm}$.) and replicated samples counted to 10,000 counts. From Table 1 it can be seen that calcium carbonate precipitates from calcium chloride alone as against the magnesium chloride mixture on average exhibit a slightly greater activity which is statistically significant $(P=0 \cdot 01)$. It is probable therefore that the precipitates from the mixed chlorides are slightly contaminated with magnesium hydroxide (not magnesium carbonate as this would tend to increase the sensitivity). Qualitative analysis shows magnesium to be present in the precipitates. The reason why magnesium chloride is effective is not understood.

I am indebted to Prof. G. E. Blackman and members of his staff for their guidance and encouragement.

Department of Agriculture,

E. C. S. Litthe

University of Oxford. ${ }^{1}$ Calvin, M., et al., 'Isotopic Carbon' (John Wiley and Sons, Inc.,
New York, 1949). 